\title{
Enantioselective Total Synthesis of (+)-Gephyrotoxin 287C
}

\author{
Miriam Piccichè, ${ }^{\dagger}$ Alexandre Pinto ${ }^{\dagger}$ Rosa Griera, Joan Bosch, and Mercedes Amat*
}

Laboratory of Organic Chemistry, Faculty of Pharmacy and Food Sciences, and Institute of Biomedicine (IBUB), University of Barcelona, 08028-Barcelona, Spain

amat@ub.edu

Supporting Information Placeholder

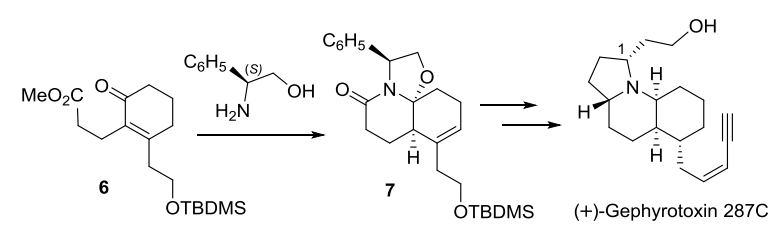

\begin{abstract}
A synthesis of (+)-gephyrotoxin 287C using $(S)$-phenylglycinol-derived tricyclic lactam 7 as the starting enantiomeric scaffold is reported. From the stereochemical standpoint, the key steps are the generation of the DHQ C-5 stereocenter by hydrogenation of the $\mathrm{C}-\mathrm{C}$ double bond, removal of the chiral inductor to give a cis-DHQ, introduction of the DHQ C-2 substituent, completion of the (Z)-enyne moiety, and generation of the $\mathrm{C}-1$ stereocenter during closure of the pyrrolidine ring.
\end{abstract}

The decahydroquinoline (DHQ) system is present in a wide array of complex natural products, which can be classified in three main categories according to their isolation source: plants (e.g. Lycopodium species; (-)-cermizine B), ${ }^{1}$ marine organisms (e.g. tunicates and flatworms; lepadins A-H) ${ }^{2}$ or amphibians $^{3}$ (Figure 1). Among the more than 800 amphibian alkaloids isolated so far, ${ }^{4}$ more than 50 incorporate a simple DHQ nucleus (2,5-disubstituted; e.g. in (-)-pumiliotoxin C), with only two of these being tricyclic: (-)-gephyrotoxin $287 \mathrm{C}$ (initially termed HTX-D) and its dihydro derivative (-)-gephyrotoxin 289B. The isolation of (-)-gephyrotoxin $287 \mathrm{C}$ in very minor amounts from the skin extracts of the Colombian frog Dendrobates histrionicus ${ }^{5}$ was first reported in $1974,{ }^{6}$ although its structure was not elucidated until 1977 , by X-ray crystallographic analysis of a sample of the hydrobromide salt. $^{7,8}$
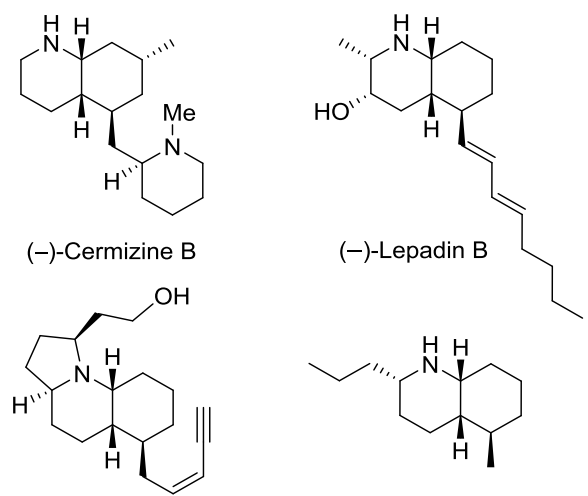

(-)-Gephyrotoxin 287C

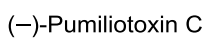

Figure 1. cis-Decahydroquinoline alkaloids.
Gephyrotoxins are characterized by a cis-DHQ core fused to a pyrrolidine ring between the DHQ 2-position and the nitrogen atom, and they incorporate a C-1 hydroxyethyl substituent and a C-6 cis-enyne or cis-diene five-carbon side chain (pyrroloquinoline numbering). The absolute configuration of (-)-gephyrotoxins was established as $1 S, 3 \mathrm{a} S, 5 \mathrm{a} S, 6 S, 9 \mathrm{a} R$. $^{7,8}$

In contrast to other amphibian alkaloids such as pumiliotoxin $\mathrm{C}$ and histrionicotoxins, gephyrotoxin $287 \mathrm{C}$ is relatively non-toxic, exhibits weak activity as a muscarinic antagonist, and acts as a moderate blocker of nicotinic acetylcholine receptor channels. ${ }^{9}$

Although the scarcity of these natural products and their neurological profile has stimulated considerable synthetic efforts in this area, ${ }^{10}$ only three enantioselective total syntheses of gephyrotoxin $287 \mathrm{C}$ have been reported to date. ${ }^{11,12}$ The first one, using L-pyroglutamic acid as the source of chirality, generated a controversy about the absolute configuration of natural gephyrotoxin $287 \mathrm{C}$, as the synthesized $1 S, 3 \mathrm{aS}, 5 \mathrm{aS}$, $6 S, 9 \mathrm{a} R$ enantiomer appeared to be dextrorotatory, ${ }^{11 \mathrm{a}}$ in contrast with the isolated natural product, which had been reported as levorotatory. ${ }^{7,8}$ However, two recent independent enantioselective syntheses unambiguously confirmed that the absolute configuration of (-)-gephyrotoxin $287 \mathrm{C}$ is $1 S, 3 \mathrm{aS}, 5 \mathrm{a} S, 6 \mathrm{~S}, 9 \mathrm{a} R$ (X-Ray analysis of the hydrochloride salt), ${ }^{11 \mathrm{~b}}$ and that (+)-gephyrotoxin $287 \mathrm{C}$ is the $1 R$ enantiomer. ${ }^{11 \mathrm{c}}$

In the context of our studies on the use of tricyclic phenylglycinol-derived oxazoloquinolone lactams as multipurpose enantiomeric scaffolds for the synthesis of DHQ-containing alkaloids, ${ }^{13}$ we report herein the synthesis of $(+)$-gephyrotoxin $287 \mathrm{C}$.

Tricyclic lactam A, bearing a functionalized two-carbon chain at the DHQ 5-position with the required 4a-H/5-H trans relationship, was envisaged as the starting enantiomeric scaf- 
fold. This lactam would be accessible by cyclocondensation of $(S)$-phenylglycinol with an appropriate cyclohexenone-derived $\delta$-keto ester. After removal of the chiral inductor and activation of the lactam carbonyl, an $\alpha, \beta$-unsaturated pentenoate substituent would be stereoselectively $(2-\mathrm{H} / 8 \mathrm{a}-\mathrm{H}$ trans $)$ installed at the DHQ 2-position. The introduction of the enyne moiety with the required $Z$ stereochemistry and the closure of the pyrrolidine ring by an intramolecular conjugate addition would assemble the tricyclic pyrroloquinoline system. A final reduction of the ester group would complete the synthesis of (+)-gephyrotoxin 287C. Scheme 1 outlines our synthetic plan.

\section{Scheme 1. Synthetic Strategy}

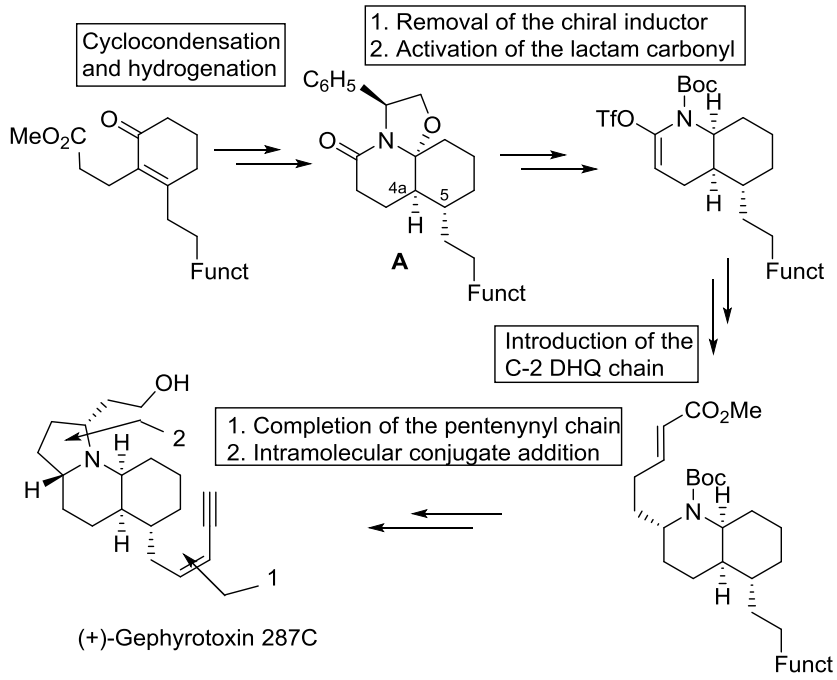

We initially targeted tricyclic lactam $\mathbf{5}$, in which the silylethyl substituent would be further elaborated to the pentenynyl chain. The required keto ester 3 was prepared in $94 \%$ yield by a one-pot procedure from the commercially available vinylsilane 2 via a $B$-alkyl-Suzuki-Miyaura cross-coupling ${ }^{14}$ involving a regioselective hydroboration with 9-BBN and a subsequent Pd-catalyzed coupling with the known ${ }^{15}$ bromo enone 1 (Scheme 2). However, cyclocondensation of keto ester 3 with $(S)$-phenylglycinol led to the expected lactam 4 in low yield, with a significant mass loss after chromatographic separation. This result was unexpected because in previous work we had successfully used keto esters containing a $\mathrm{SiMe}_{2} \mathrm{Ph}$ moiety in related cyclocondensation reactions. ${ }^{13 \mathrm{~b}}$ The subsequent reduction of the $\mathrm{C}-\mathrm{C}$ double bond of $\mathbf{4}$ also proved unsatisfactory since the hydrogenation was sluggish and occurred with concomitant reduction of the phenyl rings.

To circumvent these inconveniences, we decided to manipulate the silane moiety prior to the cyclocondensation reaction. To this end, silyl derivative $\mathbf{3}$ was converted to silyl ether $\mathbf{6}$ by Tamao-Fleming oxidation, ${ }^{16}$ followed by protection of the resulting alcohol. In this series, the cyclocondensation reaction of 6 with $(S)$-phenylglycinol and the subsequent catalytic hydrogenation of the resulting unsaturated lactam 7 took place in satisfactory overall yield $(47 \%)$ to give tricyclic lactam 8 as a single stereoisomer. ${ }^{17}$
Scheme 2. Preparation of the Starting Enantiomeric Scaffold

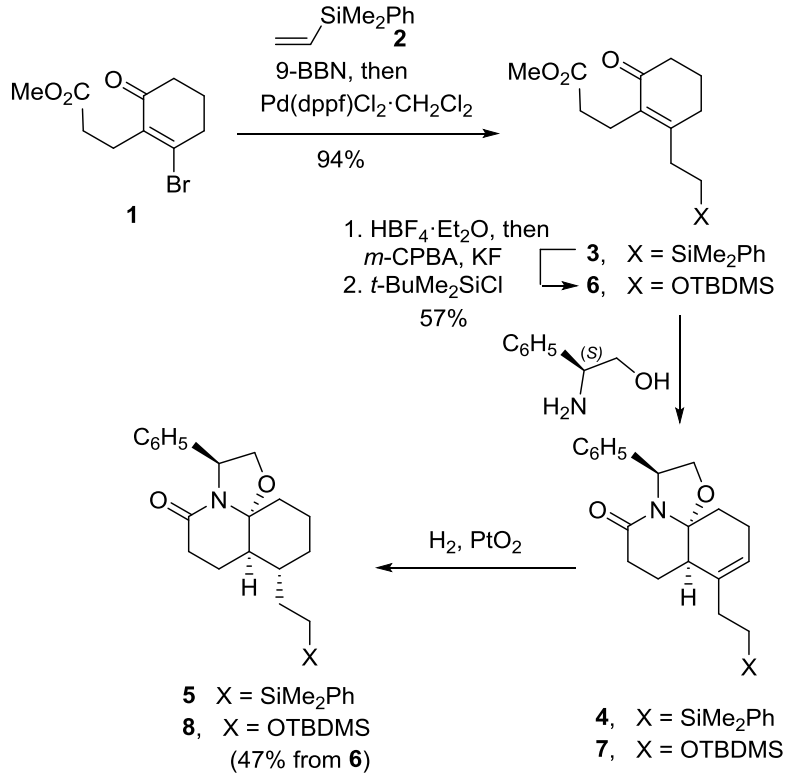

With our chiral scaffold $\mathbf{8}$ in hand, the removal of the chiral inductor was performed in two steps: alane reduction, which brought about both the steroselective reductive cleavage of the oxazolidine $\mathrm{C}-\mathrm{O}$ bond and the reduction of the lactam carbon$\mathrm{yl}$, and debenzylation by catalytic hydrogenation in the presence of $\mathrm{Boc}_{2} \mathrm{O}$. A subsequent ruthenium tetroxide promoted ${ }^{18}$ reoxidation of the resulting $N$-Boc-cis-DHQ 9, which has the required absolute configuration at the $4 \mathrm{a}, 5$, and $8 \mathrm{a}$ stereocenters, led to bicyclic lactam $\mathbf{1 0}$ (Scheme 3).

Following our synthetic plan, lactam $\mathbf{1 0}$ was converted in virtually quantitative yield to vinyl triflate 11 using Comins' protocol. ${ }^{19}$ Then, the stereoselective introduction of a substituent at C-2 was accomplished by Stille coupling of $\mathbf{1 1}$ with allyl stannane, followed by reduction of the resulting enecarbamate under $\mathrm{NaBH}_{3} \mathrm{CN}$-TFA conditions, which provided DHQ 12 as a single stereoisomer. A stereoelectronically controlled $^{20}$ axial attack of the hydride ion from the bottom face of the $N$-acyliminium intermediate $\mathbf{B}$, via a chair-like transition state in which the $\mathrm{C}-8 / \mathrm{C}-8 \mathrm{a}$ bond is axial due to the presence of the Boc group, accounts for the observed stereoselectivity.

Taking advantage of the allyl group present in 12, the pentenoate chain was completed in a three-step sequence involving the hydroboration-oxidation of the terminal olefin, oxidation of the resulting alcohol 13, and finally, a Wittig olefination. Unsaturated ester 14 was obtained in six synthetic steps and $42 \%$ overall yield from lactam $10 .{ }^{21}$

The next phase of the synthesis was the completion of the Zpentenynyl chain. This was accomplished in good yield and complete stereoselectivity by treatment of the aldehyde resulting from desilylation-oxidation of $\mathbf{1 4}$ with the known bulky 1,3-disilylpropyne $\mathbf{1 6}^{22}$ under Yamamoto's modified Peterson olefination conditions ${ }^{23}$ (Scheme 4). After removal of the Boc 

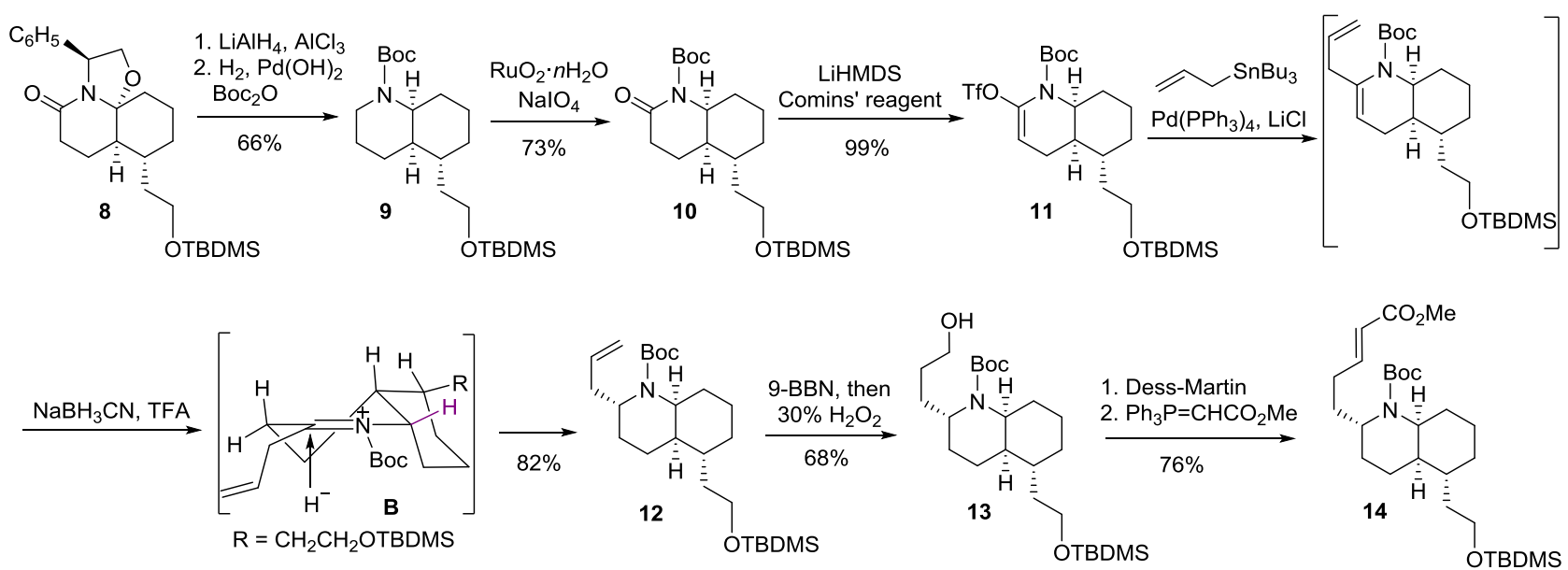

and TMS protecting groups of the resulting enyne 17, a treatment with sodium methoxide, applying previously reported conditions, ${ }^{10 a, 11 \mathrm{c}}$ brought about the desired aza-Michael cyclization, affording tricyclic ester 18. A final treatment with DIBALH, and then with $\mathrm{NaBH}_{4}$ to ensure the complete reduction of the intermediate aldehyde, ${ }^{11 \mathrm{~b}, \mathrm{c}}$ gave the target gephyrotoxin $287 \mathrm{C}$. Our synthetic gephyrotoxin $287 \mathrm{C}$, of $1 R, 3 \mathrm{a} R, 5 \mathrm{a} R 6 R, 9 \mathrm{a} S$ absolute configuration, showed NMR data coincident with those reported for the natural product ${ }^{24}$ and proved to be dextrorotatory $\left\{[\alpha]_{\mathrm{D}}{ }^{23}=+49.0\right.$ (c 0.21 , EtOH) $\}$, in agreement with the original $1 S, 3 \mathrm{a} S, 5 \mathrm{a} S, 6 S, 9 \mathrm{a} R$ assignment for the natural levorotatory enantiomer. ${ }^{7}$

Our synthesis of (+)-gephyrotoxin 287C illustrates the potential of phenylglycinol-derived tricyclic oxazoloquinolone lactams as multipurpose scaffolds for the enantioselective assembly of DHQ-containing alkaloids. After the stereoselective generation of the tricyclic lactam scaffold 7 , the synthesis is based on a series of stereoselective transformations, namely generation of the DHQ C-5 stereocenter by catalytic hydrogenation of the $\mathrm{C}-\mathrm{C}$ double bond, reductive cleavage of the oxazolidine ring to give a cis-DHQ, generation of the DHQ C2 stereocenter with stepwise introduction of the pentenoate chain, completion of the $(Z)$-enyne moiety, and generation of the $\mathrm{C}-1$ stereocenter during the closure of the pyrrolidine ring.
Acknowledgment. Financial support from the MINECO/FEDER (Project CTQ2015-65384-R) and the Generalitat de Catalunya (Grant 2014-SGR-155) is gratefully acknowledged. We also acknowledge the networking contribution from the COST Action CM1407, the MECD (Spain) for a fellowship to A. P., and the Serra Hunter programme (R. G.).

Supporting Information Available: Complete experimental procedures, copies of ${ }^{1} \mathrm{H}$ and ${ }^{13} \mathrm{C}$ NMR spectra of all new compounds. This material is available free of charge via internet at http://pubs.acs.org.

\section{REFERENCES}

$\dagger$ These authors contributed equally.

(1) (a) Ma, X.; Gang, D.-R. Nat. Prod. Rep. 2004, 21, 752-772. (b) Hirasawa, Y.; Kobayashi, J.; Morita, H. Heterocycles 2009, 77, 679729. (c) Siengalewicz, P.; Mulzer J.; Rinner, U. in The Alkaloids; Knölker, H.-J., Ed.; Elsevier: San Diego, 2013; Vol. 72, 1-151.

(2) (a) Steffan, B. Tetrahedron 1991, 47, 8729-8732. (b) Kubanek, J.; Williams, D. E.; de Silva, E. D.; Allen, T., Andersen, R. J.; Tetrahedron Lett. 1995, 36, 6189-6192. (c) Wright, A. D.; Goclik, E.; König, G. M.; Kaminsky, R. J. Med. Chem. 2002, 45, 3067-3072. (d) Davis, R. A.; Carroll, A. R.; Quinn, A. D. J. Nat. Prod. 2002, 65 , 454-457.

Scheme 4. Completion of the Synthesis of (+)-Gephyrotoxin 287C

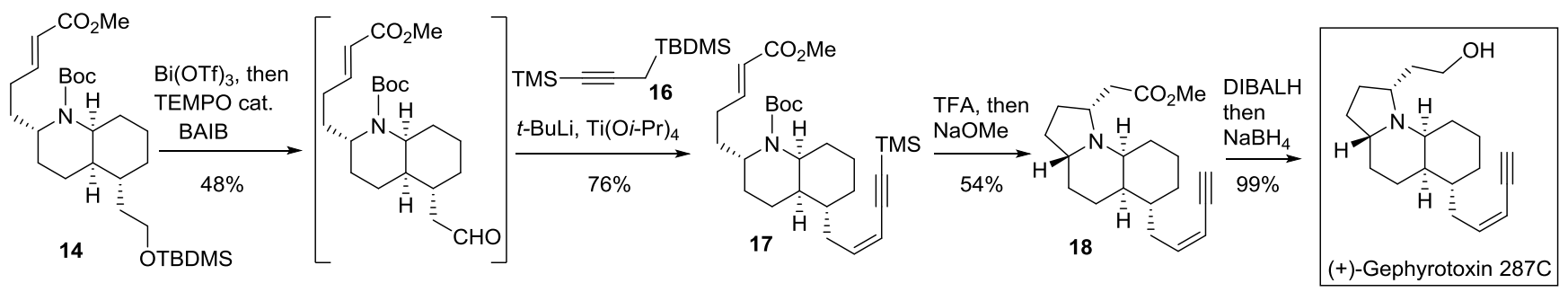


(3) Many amphibian alkaloids have also been detected in arthropods (myrmicine ants), thus suggesting a dietary source for their presence in frogs: (a) Daly, J. W. J. Nat. Prod. 1998, 61, 162-172. (b) Jones, T. H.; Gorman, J. T. S.; Snelling, R. R.; Delabie, J. H. C.; Blum, M. S.; Garraffo, H. M.; Jain, P.; Daly, J. W.; Spande, T. F. J. Chem. Ecol. 1999, 25, 1179-1193. (c) Spande, T. F.; Jain, P.; Garraffo, M.; Pannell, L. K.; Yeh, H. J. C.; Daly, J. W.; Fukumoto, S.; Imamura, K.; Tokuyama, T.; Torres, J. A.; Snelling, R. R.; Jones, T. H. J. Nat. Prod. 1999, 62, 5-21. (d) Daly, J. W.; Garraffo, H. M.; Jain, P.; Spande, T. F.; Snelling, R. R.; Jaramillo, C.; Rand, S. J. Chem. Ecol. 2000, 26, 73-85.

(4) For reviews, see: (a) Witkop, B.; Gössinger, E. In The Alkaloids; Brossi, A., Ed.; Academic Press: New York, 1983; Vol. 21, 139-253. (b) Daly, J. W.; Spande, T. F. In Alkaloids: Chemical and Biological Perspectives; Pelletier, S. W., Ed.; Wiley: New York, 1986; Vol. 4, 1274. (c) Daly, J.W.; Garraffo, H. M.; Spande, T. F. In The Alkaloids; Cordell, G. A., Ed.; Academic Press: San Diego, CA, 1993; Vol. 43, 185-288. (d) Daly, J. W. In The Alkaloids; Cordell, G. A, Ed.; Academic Press: New York, 1998; Vol. 50, 141-169. (e) Daly, J. W.; Garraffo, H. M.; Spande, T. F. In Alkaloids: Chemical and Biological Perspectives; Pelletier, S.W., Ed.; Pergamon, New York, 1999; Vol. 13, 1-161. (f) Daly, J.W.; Spande, T. F.; Garraffo, H. M. J. Nat. Prod. 2005, 68, 1556-1575.

(5) Renamed as Oophaga histrionica in 2006: Saporito, R. A., Donnelly, M. A.; Jain, P.; Garraffo, H. M.; Spande, T. F.; Daly, J. W. Toxicon 2007, 50, 757-778.

(6) Tokuyama, T.; Uenoyama, K.; Brown, G.; Daly, J. W.; Witkop, B. Helv. Chim. Acta 1974, 57, 2597-2604.

(7) Daly, J. W.; Witkop, B. Tokuyama, T.; Nishikawa, t.; Karle, I. L. Helv. Chim. Acta 1977, 60, 1128-1140.

(8) The optical rotation was measured from a sample of gephyrotoxin isolated from extracts of frogs collected in 1974. The gephyrotoxin used for the X-ray analysis had been obtained from frogs collected in the same area in 1971: see references $4 b$, c, e.

(9) (a) Mensah-Dwumah, M.; Daly, J. W. Toxicon 1978, 16, 189194. (b) Souccar, C.; Varanda, W. A.; Daly, J. W.; Albuquerque, E. X. Mol. Pharmacol. 1984, 25, 384-394. (c) Aronstam, R. S.; Daly, J. W.; Spande, T. F.; Narayanan, T. K.; Albuquerque, E. X. Neurochem. Res. 1986, 11, 1227-1240.

(10) For the synthesis of ( \pm )-perhydrogephyrotoxin, see: (a) Overman, L. E.; Fukaya, C. J. Am. Chem. Soc. 1980, 102, 1454-1456. For the synthesis of ( \pm )-gephyrotoxin 287C, see: (b) Fujimoto, R.; Kishi, Y.; Blount, J. F. J. Am. Chem. Soc. 1980, 102, 7154-7156. (c) Hart D. J.; Kanai, K. J. Am. Chem. Soc. 1983, 105, 1255-1263. (d) Overman, L. E.; Lesuisse, D.; Hashimoto, M. J. Am. Chem. Soc. 1983, 105, 5373-5379. (e) Shirokane, K.; Wada, T.; Yoritate, M.; Minamikawa, R.; Takayama, N.; Sato, T.; Chida, N. Angew. Chem. Int. Ed. 2014, 53, 512-516. (f) Shirokane, K.; Tanaka, Y.; Yoritate, M.; Takayama, N.; Sato, T.; Chida, N. Bull. Chem. Soc. Jpn. 2015, 88, 522-537.

(11) (a) Fujimoto, R.; Kishi, Y. Tetrahedron Lett. 1981, 22, $4197-$ 4198. 1981. (b) Chu, S.; Wallace, S.; Smith, M. D. Angew. Chem. Int. Ed. 2014, 53, 13826-13829. (c) Nemoto, T.; Yamaguchi, M.; Kakugawa, K.; Harada, S.; Hamada, Y. Adv. Synth. Catal. 2015, 357, $2547-2555$

(12) For formal enantioselective syntheses, see: (a) Wei, L.-L.; Hsung, R. P.; Sklenicka, H. M.; Gerasyuto, A. I. Angew. Chem. Int. Ed. 2001, 403, 1516-1518. (b) Santarem, M.; Vanucci-Bacqué, C.; Lhommet, G. J. Org. Chem. 2008, 73, 6466-6469. (c) Miao, L.; Shu, H.; Noble, A. R.; Fournet, S. P.; Stevens, E. D.; Trudell, M. L.
Arkivoc 2010, viii, 6-14. (d) Pichette, S.; Winter, D. K.; Lessard, J.; Spino, C. J. Org. Chem. 2013, 78, 12532-12544.

(13) (a) Amat, M.; Fabregat, R.; Griera, R.; Florindo, P.; Molins, E.; Bosch, J. J. Org. Chem. 2010, 75, 3797-3805. (b) Amat, M.; Ghirardi, E.; Navío, L.; Griera, R.; Llor, N.; Molins, E.; Bosch, J. Chem. Eur. J. 2013, 19, 16044-16049. (c) Amat, M.; Pinto, A.; Griera, R.; Bosch, J. Chem. Eur. J. 2015, 21, 12804-12808. (d) Pinto, A.; Griera, R.; Molins, E.; Fernández, I.; Bosch, J. Amat, M. Org. Lett. 2017, 19, 1714-1717.

(14) Miyaura, N.; Ishiyama, T.; Sasaki, H.; Ishikawa, M.; Satoh, M.; Suzuki, A. J. Am. Chem. Soc. 1989, 111, 314-321.

(15) Amat, M.; Fabregat, R.; Griera, R.; Bosch, J. J. Org. Chem. 2009, 74, 1794-1797.

(16) Jones, G. R. Tetrahedron 1996, 52, 7599-7662.

(17) The absolute configuration of unsaturated and saturated tricyclic lactams related to $\mathbf{4}, \mathbf{7}$, and $\mathbf{8}$ (methyl substituent instead of $\mathrm{CH}_{2} \mathrm{CH}_{2} \mathrm{X}$ at the DHQ 5-position) was unambiguously determined by $\mathrm{X}$-ray crystallography. ${ }^{13 a}$

(18) For the ruthenium tetroxide oxidation of $N$-acyl cyclic amines to the corresponding $N$-acyl lactams, see: (a) Sheehan, J. C.; Tulis, R. W. J. Org. Chem. 1974, 39, 2264-2267. (b) Moriyama, K.; Sakai, H.; Kawabata, T. Org. Lett. 2008, 10, 3883-3886.

(19) (a) Comins, D. L.; Dehghani, A. Tetrahedron Lett. 1992, 33, 6299-6302. (b) Foti, C. J.; Comins, D. L. J. Org. Chem. 1995, 60, 2656-2657.

(20) Deslongchamps, P. In Stereoelectronic Effects in Organic Chemistry; Baldwin, J. E., Ed. Pergamon: Oxford, 1983.

(21) An alternative, more direct route involving a Pd-catalyzed Suzuki coupling of triflate $\mathbf{1 1}$ with boronic acid $\mathbf{1 5}\left[\mathrm{Pd}(\mathrm{dppf}) \mathrm{Cl}_{2}, \mathrm{Ag}_{2} \mathrm{O}\right.$, $\mathrm{K}_{2} \mathrm{CO}_{3}$ ], followed by $\mathrm{NaBH}_{3} \mathrm{CN}-\mathrm{TFA}$ reduction of the resulting enecarbamate, provided DHQ 14 in only $26 \%$ yield.<smiles>COC(=O)C=CCCB(O)O</smiles>

(22) Corey, E. J., Rücker, C. Tetrahedron Lett. 1982, 23, 719-722.

(23) (a) Ishiguro, M.; Ikeda, N.; Yamamoto, H. J. Org. Chem. 1982, 47, 2225-2227. (b) Furuta, K.; Ishiguro, M.; Haruta, R.; Ikeda, N.; Yamamoto, H. Bull. Chem. Soc. Jpn. 1984, 57, 2768-2776.

(24) For the complete ${ }^{1} \mathrm{H}$ - and ${ }^{13} \mathrm{C}-\mathrm{NMR}$ assignment of gephyrotoxin 287C, see: Edwards, M. W.; Bax, A. J. Am. Chem. Soc. 1986, 108, 918-923. 